\title{
Research on the Design and Detailing of a Re-constructional High-rise Building Structure Project Reconstruction
}

\author{
Ling Yuhong ${ }^{1}$, Lin BiaoYi ${ }^{2}, \mathrm{Ke} \mathrm{Yu}^{1}$ and Chen QingJun ${ }^{2,3, *}$
}

${ }^{1}$ Architectural Design and Research Institute of South China University of Technology, Guangzhou 510640, China; ${ }^{2}$ School of Civil and Transportation Engineering, South China University of Technology, Guangzhou, 510641; ${ }^{3}$ State Key Laboratory of Subtropical Building Science, Guangzhou, 510641, China

\begin{abstract}
This paper introduced the reconstruction practice and detailing of a high-rise reinforced concrete frame-shear wall structure. To fully utilize the old structure and meet the requirement of the reconstructed structure, certain measures have been put forward. The enlarging of concrete pile cap and adding strip foundation-beam were used to support the new added shear wall. The reconstruction concept detailing of the roof of basement, the enlarging of the beam or column sections and the application of the inclined column are introduced. The whole structure analysis shows that the reconstructed structure is safe enough to meet all the requirement of the designing code and the settlement observation shows that the deformation of the whole structure in gravity is small. The paper shows the design and detailing of the reconstructed engineering is effective and will be valuable to the similar engineering structures.
\end{abstract}

Keywords: Design, detailing, frame-shear wall structure, reconstruction of structure, settlement observation.

\section{STRUCTURE OVERVIEW}

This project is located in the junction of FangCun of Guangzhou and NanHai of Foshan, and south of the Guangfo Expressway. The original project is designed as a synthesize building, which has one storey basement (functioning as equipment room and garage), 12 storeys commercial buildings and two 28 storeys business-living buildings. The plan of the original project is shown in Fig. (1). The total building area of the original project is about $78,000 \mathrm{~m}^{2}$. After completing the roof of basement work in December, 1994, the original project was shut down due to various reasons. The project restarted construction in June 2007, and passed the completion acceptance of construction at the end of 2008. At the beginning of the restructuring, the developers entrusted the Construction Science Research Institute of Guangdong Province to test the safety of the original structure. The results show that the reconstruction condition is suitable. However, this project is redesigned according to the testing results and the new planning of the Guangfo Expressway. The new project is divided into two districts, namely as A-district and Bdistrict. A-district includes three 17 storeys frame-shear wall structure residential buildings, while B-district includes four 10 storeys residential buildings. Total building area of the project is about $54,000 \mathrm{~m}^{2}$, the first storey is the shopping mall, in order to create a large space the structural transfer floor is adopted on the second storey, which leaded to a great difference between the new and the old vertical component. The plan of this new project is shown in Fig. (2).

*Address correspondence to this author at the Training building, room 306, South China University of Technology, Guangzhou, 510641, China;

Tel: 86+13533335670; E-mail: qjchen@ @scut.edu.cn

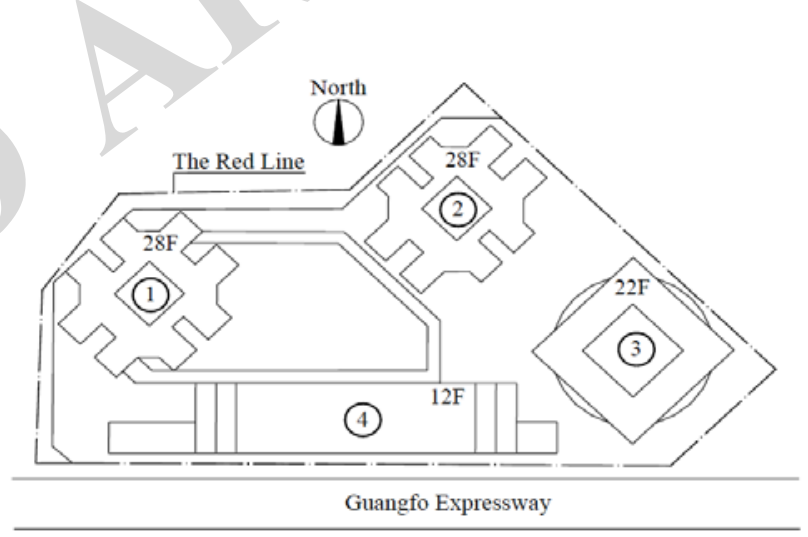

Fig. (1). The plan of original project.

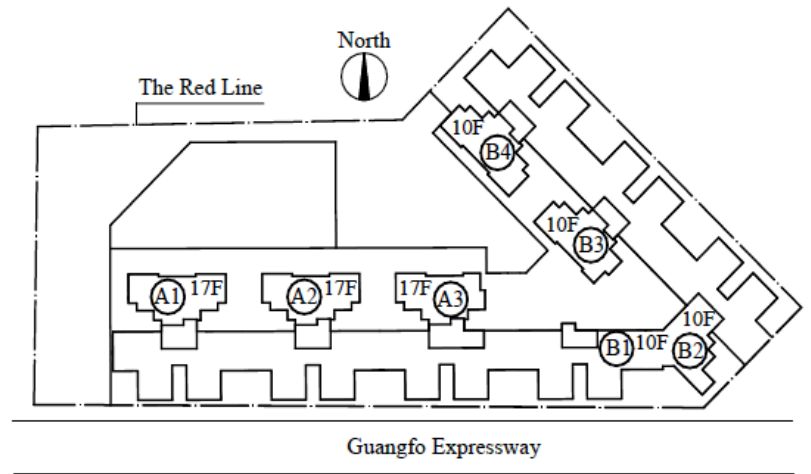

Fig. (2). The plan of new project.

\section{STRUCTURE DESIGN}

According to some references, the key problem of reconstruction project is to coordinate the relationship between demolishing and utilizing the original structure [1-7]. Basing 
on this project, the main difficulty is to fully use the original structure and cope with the difference of vertical component.

\subsection{Foundation Design}

The original project had been designed to be supported by 212 manual hole digging piles, whose bearing stratum is the slightly weathered rock. The new design uses 179 piles instead, and the bearing capacity of all the piles can meet the requirement, according to the testing results. However the design is totally different from the original one. For example, most towers are deviated from the original ones, and some towers have no foundation to support the shear wall above. In order to fully utilize the pile foundation to reduce the project cost, after coordinating with architectural technician, two methods are adopted to support the new shear wall.

\section{(1) Adding concrete pile cap to support shear wall}

In the original design, there was no large concrete pile cap in B3 tower, so the concrete pile cap was added to support shear wall above. In the design of cap, the centroid of the cap should be as close as to the centroid of the shear wall. New piles were set under the cap to support the shear wall above. One profile of added concrete cap is shown in Fig. (3).

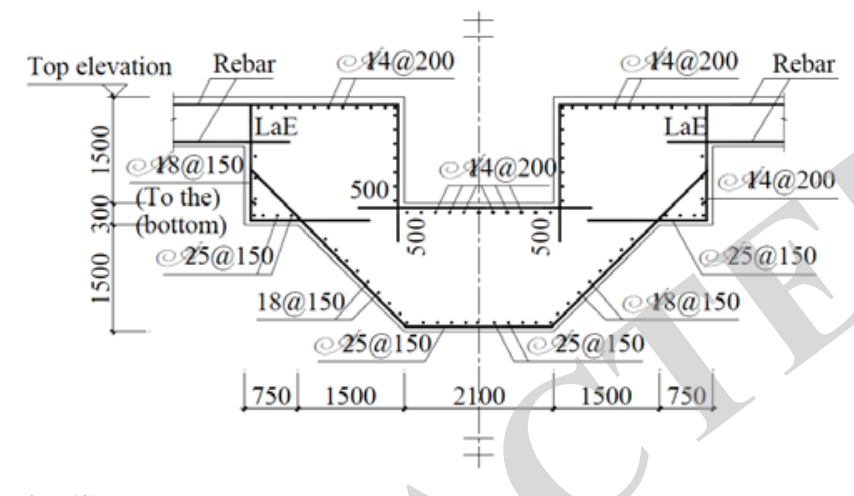

Fig. (3). The profile of added concrete cap.

(2) Adding strip foundation-beam to support shear wall

In order to use the original piles, strip foundation-beam was added on the original piles to support shear wall. The height and width of the strip foundation-beam were calculated by the capacity requirement. By connecting with frame column and pile foundation, the strip foundation beams became a closed system. In order to reduce the torque caused by eccentricity, the centroids of the frame columns or the shear wall should align with the center line of the strip foundation beam. In the design of the foundation beam, firstly, it should be treated as a frame-supported beam to sustain the vertical load; secondly, the moment at the bottom of the column should be included. Furthermore, to ensure the integrity of the supporting structure, the floor was heightened by $180 \mathrm{~mm}$ on the top of the foundation beam. The foundation beam is shown in Fig. (4).

\subsection{The Design and Detailing Requirement of the Roof of Basement Structure}

(1) Floor

As mentioned before, the roof of basement had been completed when the original project stopped. Many floors were found to be in poor construction quality during the inspection of the structure. The crack of the floors and the exposed reinforcements were found everywhere. Considering safety and durability of structure, most of the floors were demolished and poured again. Concrete-cutting technique was adopted to cut the whole concrete floor into sections, and small chisels were used for demolition near the beam. The top-bars of the floors were cut off and the bottom-bars were retained $800 \mathrm{~mm}$ from the side of beam. The new floor's surface was $20 \mathrm{~mm}$ higher than the original one. The new top-bars were set above the beam, while the new bottom-bars were lapped with the retained original bottom-bars. The details of the reinforcement of the floors are shown in Fig. (5).

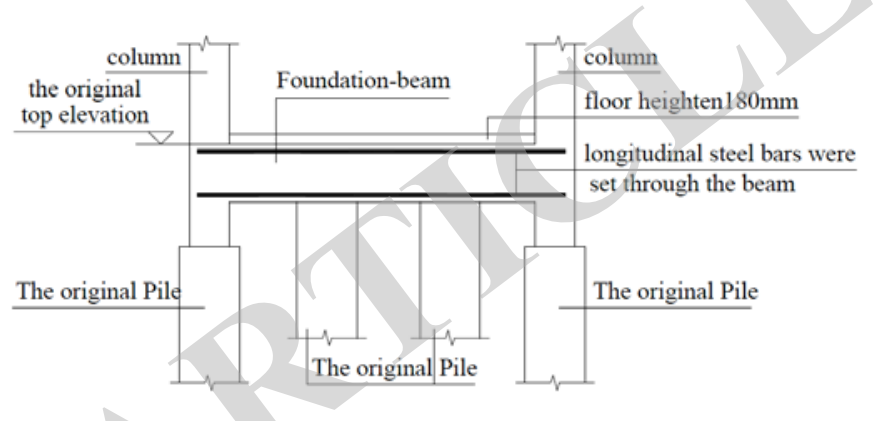

Fig. (4). The setting of foundation-beam.

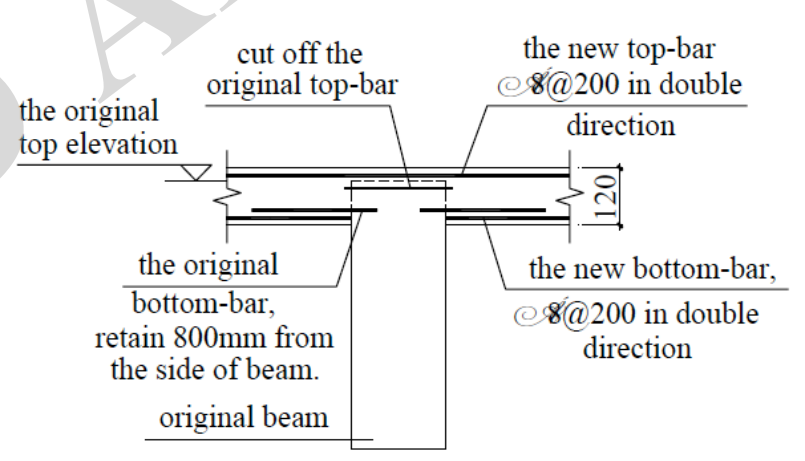

Fig. (5). The reinforcement of the floors.

\section{(2) Enlarging the beam section}

Because some beams cannot meet the requirement for the new design, enlarging the sections instead of demolishing them is a relatively economical and convenient way. The method of enlarging the section of beam is shown in Fig. (6). Firstly, the workers would rough the surface of concrete; the depth of roughing is as same as the steel's protection layer. Then opening stirrups were planted into the beam and welded close at both ends. The added longitudinal steel bars were not necessary to be planted into the columns, as the sagging moment of the beam is resisted by the top-bars of original beam. Generally, beams should be heightened more than $200 \mathrm{~mm}$ and be widened $60 \mathrm{~mm}$ to $80 \mathrm{~mm}$ to ensure the quality of pouring concrete.

\section{(3) Enlarging the column section}

The main reason for enlarging the section of column is that the location of column is inconsistent with the new added shear wall above. If the new shear wall is not far away from the column, enlarging the column section can avoid complication of force transfer. The method of enlarging the 
column section is shown in Fig. (7). The column can be enlarged on two sides or four sides.

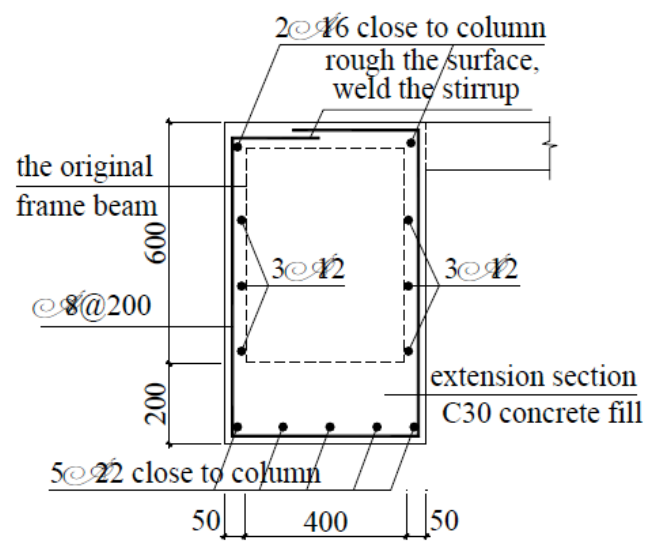

Fig. (6). The method of enlarging the section of beam.

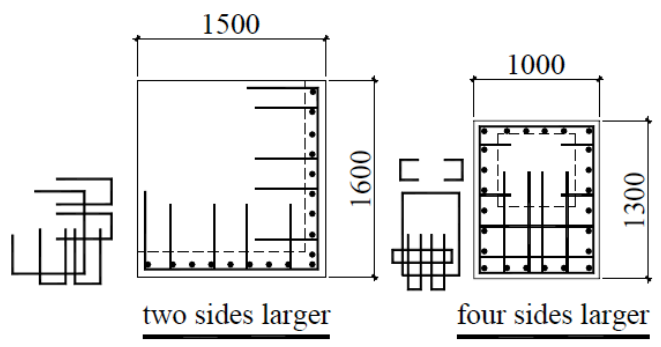

Fig. (7), The method of enlarging the column section.

(4) Adopting inclined column for transferring

If enlarging the column section is not economical or has a detrimental influence on the building's function, inclined column transferring is a better way to solve the problem. The inclined column transferring is shown in Fig. (8). Because the inclined column will generate a major horizontal pushing force, the inclination angle should be controlled and measures should be considered to resist this force. At the roof of basement, the axial force of column can be decomposed to horizontal pushing force $\mathrm{F}_{1 \mathrm{X}}$ and axial force of inclined column $F_{N} \cdot F_{1 X}$ is resisted by the roof of the basement. The frame beams that are connected to the inclined column are under tension-compression stresses at either ends, respectively, so the longitudinal steel bars should be set through the beam and the corresponding roof of basement should also be thickened. At the basement slab, $\mathrm{F}_{\mathrm{N}}$ can be decomposed to horizontal pushing force $\mathrm{F}_{2 \mathrm{X}}$ and vertical pressure $\mathrm{F}_{2 \mathrm{Y}}$. According to the calculation results, $F_{2 X}=F_{N} \times \cos \beta, \beta$ is the inclination angle. The thickness of the original basement slab is $700 \mathrm{~mm}$, and its steel bars are set in double direction through the slab by $\hat{M} 20 @ 200$ which are enough to transmit $\mathrm{F}_{2 \mathrm{X}}$ to the foundation.

\section{STRUCTURE ANALYSIS}

Reinforced concrete frame-shear wall structure was adopted in this reconstructed building. In order to meet the utilization need of the first floor and basement, frame supporting columns are set in the first storey and basement, while the transferring storey was arranged in the second storey.

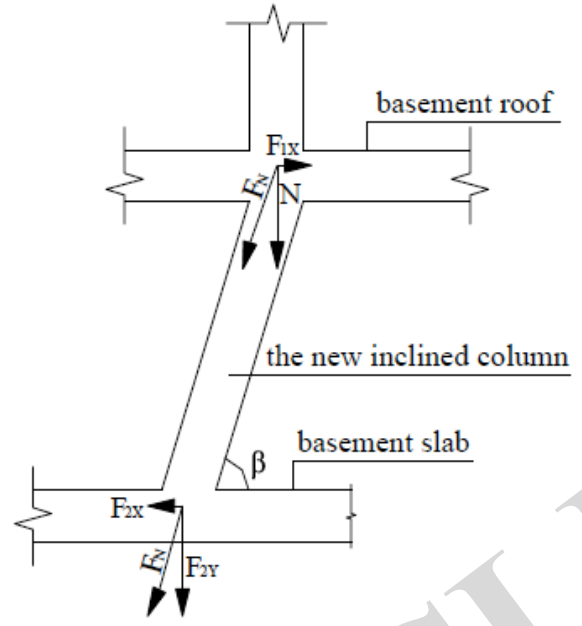

Fig. (8). The inclined column transferring.

In order to accurately analyze the force distributions of the new structure, both software YJK and ETABS are used to conduct the analysis. The fixing of structure is set on the roof of basement, and both the translation-torsion coupling and construction load are considered during analysis. The analysis results of the building are listed in Table $\mathbf{1 .}$

It can be seen from Table 1 that the ratio of the third period based on torsion to the basic period based on translation is less than 0.9 , the ratio of the maximum inter-storey displacement to the average inter-storey displacement is less than 1.5, and both meet the requirement of the Technical Specification for Concrete Structures of Tall Buildings (JGJ3-2010) [8].

\section{SETTLEMENT OBSERVATION}

To observe the settlements and validate the stability of original pile foundation, settlement observation points are arranged near the corner of buildings, marked as " $\boldsymbol{\Delta}$ ", as shown in Fig. (9). The observation work started on June, 2007 and ended on December, 2008. Four points were chosen to illustrate the settlement, named from $\mathrm{C} 1$ to $\mathrm{C} 4$, as shown in Fig. (10).

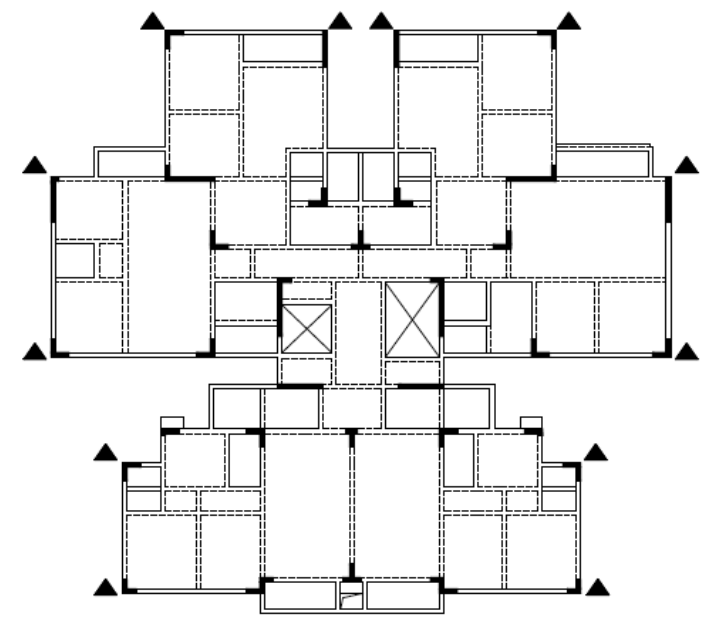

Fig. (9). Settlement observation point layout. 
Table 1. Vibration characteristics, Displacement and Internal force for building.

\begin{tabular}{|c|c|c|c|c|c|}
\hline \multirow{2}{*}{ Vibration characteristics } & \multicolumn{3}{|c|}{ Basic period (s) / Translational coefficient } & $1.2286 / 0.96$ & $1.2506 / 0.99$ \\
\hline & \multicolumn{3}{|c|}{ Third period (s) / Translational coefficient } & $0.9404 / 0.04$ & $1.0156 / 0.04$ \\
\hline \multirow{5}{*}{ Displacement characteristics } & \multirow{3}{*}{$\begin{array}{l}\text { Maximum of inter-storey drift (at corre- } \\
\text { sponding storey number) }\end{array}$} & \multirow{2}{*}{ Earthquake } & $X$ & $1 / 2100(7)$ & $1 / 2139(6)$ \\
\hline & & & $Y$ & $1 / 2339(9)$ & $1 / 2499(9)$ \\
\hline & & Wind load & $X$ & 1/3727(6) & $1 / 4108(6)$ \\
\hline & \multirow{2}{*}{$\begin{array}{l}\text { Maximum to average inter-storey drift Ratio } \\
\text { (at corresponding storey number) }\end{array}$} & \multirow{2}{*}{ Wind load } & $X$ & $1.16(2)$ & $1.06(3)$ \\
\hline & & & & $1.01(2)$ & $1.03(1)$ \\
\hline \multirow{4}{*}{$\begin{array}{l}\text { Internal force at bottom of the } \\
\text { structure }\end{array}$} & \multirow{2}{*}{ Shear force $(\mathrm{kN})$} & \multirow{2}{*}{ Earthquake } & $X$ & 2357.08 & 2403.0 \\
\hline & & & $Y$ & 2473.65 & 2553.0 \\
\hline & \multirow{2}{*}{ Moment (kN.m) } & \multirow{2}{*}{ Earthquake } & $X$ & 69267.98 & 72360.0 \\
\hline & & & $Y$ & 71345.82 & 73280.0 \\
\hline
\end{tabular}

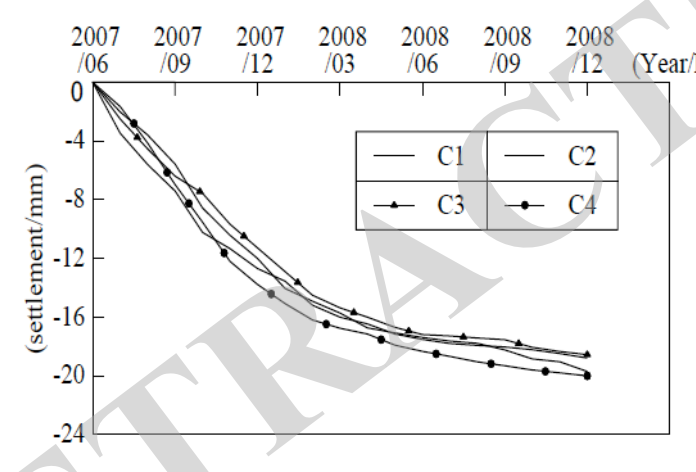

Fig. (10). Settlement curve.

According to the settlement observation curve, small settlements were observed. The point $\mathrm{C} 4$ showed the largest cumulative settlement, equal to $20.00 \mathrm{~mm}$, while point $\mathrm{C} 3$ showed the smallest cumulative settlement, equal to $15.10 \mathrm{~mm}$. The average settlement of all observation points is equal to $16.32 \mathrm{~mm}$. According to the settlement distributions, differential settlements between observation points are small. The maximum differential settlement between point $\mathrm{C} 3$ and C4 is only $4.90 \mathrm{~mm}$, which is less than the limited value $0.002 \mathrm{~L} \mathrm{~mm}$ ( $\mathrm{L}$ is the distance between the adjacent settlement observation point) according to Code for Design of Building Foundation [9]. The maximum differential settlement between the last two observations (30 days interval) is $0.18 \mathrm{~mm}$. The settling velocity is equal to $0.006 \mathrm{~mm} /$ day, less than the requirements for a building in steady state sedimentation (less than $0.02 \mathrm{~mm} /$ day) according to Code for
Building Deformation Measurement of Building and Structure [10].

Up till now, this building has been in existence for almost 8 years, but none of the adverse effects caused by settlement exist.

\section{SUMMARY}

This paper introduced the reconstruction practice and detailing of a high-rise reinforced concrete frame-shear wall structure. To fully utilize the old structure and meet the requirement of the new structure, certain measures have been put forward. The enlarging of concrete pile cap and adding strip foundation-beam were used to support the new added shear wall. The reconstruction concept detailing of the roof of basement, the enlarging of the beam or column sections and the application of the inclined column are introduced. The whole structure analysis shows that the reconstructed structure is safe enough to meet all the requirement of the designing code and the settlement observation shows that the deformation of the whole structure in gravity is small. The above discussion shows the design and detailing of the reconstructed engineering is effective and will be valuable to the similar engineering structures.

\section{CONFLICT OF INTEREST}

The authors confirm that this article content has no conflict of interest. 


\section{ACKNOWLEDGEMENTS}

Funding for this research project was provided by the State Key Lab of Subtropical Building Science, South China University of Technology (Project No. 2014KB28, 2013ZC19) and the Fundamental Research Funds for the Central Universities (2014ZZ0026). The support for the research acknowledged with thanks.

\section{REFERENCES}

[1] J. Shan, "Optimization design and seismic appraisal of reconstructional high-rise building structure," Architectural Structure, (in Chinese) no. 3, 2005

[2] L. Rong, "The reconstruction practice and detailing of a high-rise building structure," Architecture of ShanXI, (in Chinese) no.18, 2003.

[3] R. Zhang, W. Yi, Y. Ying, J. Tao, "Analysis and Design on Reconstruction of Unfinished High-Rise Building," Architecture of JiangSu, (in Chinese) 2013
[4]

C.H. Qiu, J.P. Liu, S.R. Xie, "The reconstruction practice and detailing of an unfinished building," Sichuan Building Science, (in Chinese) 2007.

[5] E.K. Zou "Design and Construction of the Unfinished Building Engineering's Reconstruction andReinforcement," Earthquake Resistant Engineering and Retrofitting, (in Chinese) vol. 35, no. 5, 2013.

[6] Y.X. Zhang, L.J. Guo "Structure design and practice on reinforcement of an unfinished building in GuangXi province.," Building Structure, (in Chinese), vol. 44, 2014.

[7] H.H. Chen, "Planning of Reconstruction Project for Uncompleted High-Rise Building," Archtectural Construction, (in Chinese) vol. 36, no. 7, 2014.

[8] The Ministry of Construction of People's Republic of China. JGJ3 2010 Technical specification for concrete structures of tall buildings. Beijing: China Archtectural and Building Press, 2010.

[9] The Ministry of Construction of People's Republic of China. GB50009-2012 Load code for the design of building structures. Beijing: China Archtectural and Building Press, 2012.

[10] The Ministry of Construction of People's Republic of China. JGJ/T 8-97 Code for deformation measurement of building and structure. Beijing: China Archtectural and Building Press, 1997.

Received: September 16, 2014

Revised: December 23, 2014

Accepted: December 31, 2014

(C) Yuhong et al.; Licensee Bentham Open.

This is an open access article licensed under the terms of the Creative Commons Attribution Non-Commercial License (http://creativecommons.org/licenses/by-nc/3.0/) which permits unrestricted, non-commercial use, distribution and reproduction in any medium, provided the work is properly cited. 